\title{
Discourse Analysis of Origin and Distribution of Coffee Arabica
}

\section{Endalkachew Lelisa Duressa}

Department of History and Heritage Management, College of Social Science and Humanities, Bule Hora University, Bule Hora, Oromia, Ethiopia endalkld@gmail.com

Abstract: This Review primarily focuses on 'Discourse Analysis of Origin and Distribution of Coffee Arabica'. The Significance of this review is to present the summary of existing information on the origin and expansion of Coffee Arabica around the globe and to minimize the degree of controversies among scholars. Information has been drawn from the works of several authors and oral traditions. For the historical root of coffee and its discovery, there is no clear direction. Still it is a controversial one among different scholars. However, there are two competing local areas, which have recently emerged in Southwestern parts of Ethiopia. These are Mankira of the present Kaffa zone and Coccee of the present Jimma zone. However, these study showed that the former Limmu Awraja of Gomma district, Coccee Guddaa kebele at a site called 'katta muuduu ga'a' is said to be the historical origin of coffee Arabica. There is no enough studies showing and focus on above controversies on coffee distribution around the world. It is not yet clear how coffee spread from its birth place of Ennarya regions to other parts of Ethiopia. It believed that it was during the Oromo expansion of the $16^{\text {th }}$ century that coffee spreading out in Ethiopia regions. Later, it was probably by long distance trade of the $19^{\text {th }}$ century that coffee disseminated. Next, coffee spread to the rest of the world by Arab merchants and the European colonizers. The data in this study consisted of the written and oral sources. Secondary data sources were collected by assessing published and unpublished materials. The available oral traditions were used as sources of data in reviewing the origin and expansion of coffee in southwestern Ethiopia. After that, the data would be described, expressed and articulated qualitatively. All the data would be analyzed carefully and interpreted in accordance with the standardized canons of the social science disciplines based on the nature of information obtained.

Keywords: Ennarya, Kaffa, Jimma, Bun, Bunnaa, Bunna, Mankira, Coccee INTRODUCTION

Ethiopia is the primary center of genetic diversity and the top coffee growing countries in the world. Coffee Arabica is the reward of nature to Ethiopian and Ethiopia in its turn to the world. The most dominant agrarian export commodity of the country has been coffee. Before the last two decades, it was the single most important crop in the economy of the country and contributing about $55-60 \%$ of the foreign exchange earnings and more than $30 \%$ of the government direct revenue. Ethiopia is one of the oldest coffee producer, consumer, and exporter in the world. Over $90 \%$ of the total coffee production came from the small scale private holders and less than $4 \%$ produced by the state farms of Coffee Plantation Development Enterprise (CPDE) [1].

There are four types of coffee production systems in Ethiopia. These are: garden coffee (50\%), forest coffee $(10 \%)$, semi-forest coffee (35\%) and plantation coffee farms(5\%). The country production is /was dominated by small holders, who produce largely for their own consumption. Almost $50 \%$ of the total coffee output is/was consumed domestically and the balance is exported. Ethiopia ranks first in coffee consumption in Africa. The major coffee producing regions in southwest Ethiopia are Illubabor, Kaffa, Limmu, Jimma, Wollaga, and parts of Benchi Maji zone [2]. Western and southwestern Ethiopia coffee type's are/were mainly, Lekemte and Jimma 
Discourse Analysis of Origin and Distribution of Coffee Arabica

sun dried coffee, Limmu, Tepi and Bebeka washed Coffee are the main exportable coffee [3]. However, the change and continuities of coffee production Oromo of in Ethiopia got less attention from scholars. Due to population pressure and land scarcity good quality coffee production such as garden and forest coffee production are now on the way to decline.

\section{DESign AND METHOdOLOGY}

The data in this study consisted of the written and oral sources. Secondary data sources were collected by assessing published and unpublished materials. In this category, the attempt was first started with reading written materials in which both historical and agricultural studies are very important. Historical reconstruction on a certain topic of oral community requires a close assessment of oral traditions using the available written sources for cross-checking. Scholars argued that, "All human history is oral in origin." Oral tradition is resourceful historical source that refers to human actions reported through speech and handed down from generation t o generation. A critical use of Oral traditions helps scholars to reconstruct history of certain society [4]. This was followed by conducting field research among the Kaffa, Jimma and Limmu, areas. In this study, the available oral traditions were used as sources of data in reviewing the origin and expansion of coffee in southwestern Ethiopia. After that, the data would be described, expressed and articulated qualitatively. All the data would be analyzed carefully and interpreted in accordance with the standardized canons of the social science disciplines based on the nature of information obtained.

\section{CONCEPTUAL FRAMEWORK}

\section{The Origin of Coffee}

According to the study made by botanists and geneticists due to the existence of diverse variability, the natural coffee populations considered as Coffea arabica, C. canephora, C. stenophylla, C. tnguebariae, and C. liberica [5], [6]. But, from recent commercial importance of green coffee market and production, the two species of Coffea Arabica and Coffea canephora are dominating world coffee production and marketing [7], [8], [9]. For the historical root of Coffee Arabica and its discovery, there is no clear direction. Its exact origin has not yet been received definite historical study. In fact, this does not mean that none of the researches conducted so far directly have attempted to provide general hint about its origin. It is to say, the issue is still a controversial one among different scholars. The main purpose of this Study is thus to analyze primary and secondary sources on the origin of coffee on one hand and to provide clear direction about its exact origin. There is no accurate account of the origins of coffee plant. There is general agreement among historians that coffee was first discovered in the forest of southwestern part of Ethiopia. According to few scholarly works, South Western Ethiopia, particularly the northern Kaffa province areas; the former Ennarya region of Jimma and Limmu Awraja are said to be the birth place of coffee Arabica [10], [11], [12].

As various secondary sources indicates, the former Ennarya regions (later Limmu Ennarya) was located between the river valleys of Gojeb in the south, Wama River in the north, Gibe in the east and the Upper Dedhessa River in the west [13], [14]. There are different other claims that reveal locate coffee Arabica is origin at different areas. For instance, there is a claim that former Bunno Bedelle awraja, the current Bedelle area is the original homeland of coffee [15]. Nevertheless, this claim seems to be true due to the similarity of Bunno Bedelle natural environment with Ennarya region. There is also another argument which revealed the birth place of coffee to the Boma plateau of eastern Sudan which borders on southwest Ethiopian highlands. Even if, there is a common boundary between the two areas they are not exactly the same. May be both areas have similar environmental condition that is favorable for coffee production. Similarly there is also claim that attempted to connect coffee's origin with the South Arabia; Yemen is the birth place of coffee [16]. All botanists, who have explored the forests in the southwestern highlands of Ethiopia reported that the country is the center of diversity of $C$. Arabica [17]. 


\section{Discourse Analysis of Origin and Distribution of Coffee Arabica}

There is also belief that Coffee plant was originated in Arabia. According to these scholars, since coffee knowledge as a beverage and cultivation was obtained first in Arabia. Even if, this claim seems true, it is too shallow. They used Coffee drinking habit, the scientific name given by Linnaeus and coffee cultivation in Arabia as an evidence which were the phenomena of $15^{\text {th }}$ Century. Before, $15^{\text {th }}$ Century there is strong claim that the Oromo people of Ennarya regions used Coffee. Credible evidence exists to show that coffee drinking took place in the Sufi Monasteries of Yemen in the mid1 $5^{\text {th }}$ Century and we still use the term Mocha (Yemen port) in coffee references today[18]. Harar is widely consider as the origin of coffee plant was the region of Ethiopia, Kenya or Sudan where local populations may have cultivated the plants [19]. He used only the degree of cultivation and wide areas of Africa for the origin of coffee. Of course, coffee is evergreen plant and it may survive under similar environments. It may distributed by agents of wind and wild birds.

Thus, foreign and Ethiopia historians again and again argue that, coffee Arabica was evolved in southwestern forest particularly, Ennarya region [20]. According to different studies, the origin of coffee is around Suntu (the current LimmuKossa) Coffee State Farm of Ennarya region in Gejeb kebele which considered as motherlands of coffee Arabica.In these areaswe can find mother tree (Mootii Bunaa) of about 200 years age which still yields enough production. Even, local informants told as many other similar mother coffee trees were cleared by local people for the purpose of house construction. These tell us good evidence as the former Ennarya [Limmu Ennarya] have been the historical origin of coffee [21].

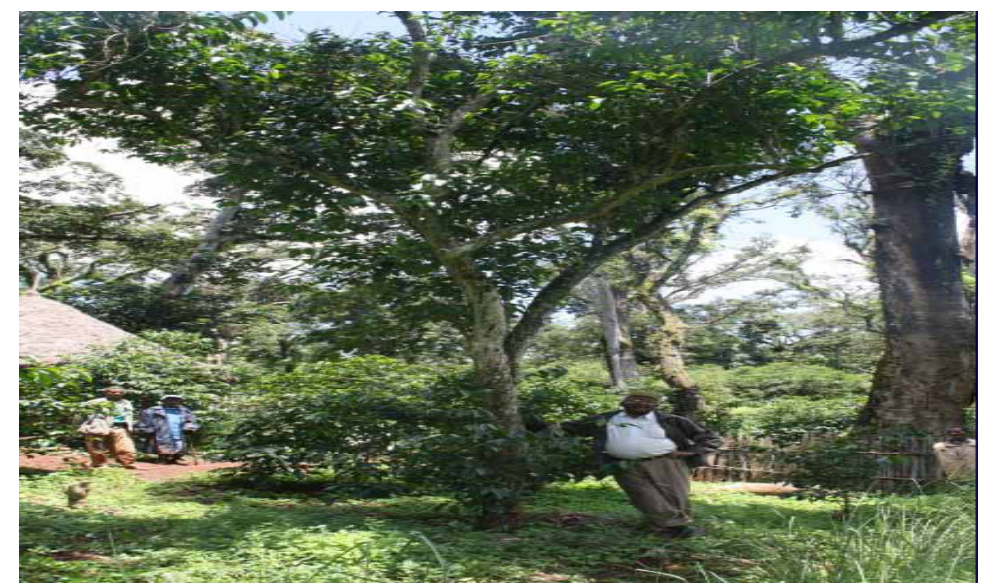

Fig.1. Mother Coffee Tree (MootiiBunaa) in Suntu State Farm in Limmu Saqqa district Soures: [22]

An estimated 200 years-old coffee tree in Gejib forest, Saqqa district located in Suntu state farm: it has 14 meters height and $85 \mathrm{~cm}$ circumference.

\section{Local Legends about first Discovery of Coffee}

There are no satisfactory local sources to show the historical root of coffee Arabica in Ennarya regions. However, there are two competing local areas "Mankira of the present Kaffa zone and Coccee of the present Jimma zone". These areas are part of the former Kaffa Kiflehager for a long period of the time and they separated since the past two decades and became part of distinct administrative zones, current Kaffa and Jimma zones, respectively[23] .There are many oral traditions or legends that support this views.Among these the Kaffaand Oromo traditions are the main competing local legends. The first locally oriented source about the origin of coffee is an account that reveals the current Kaffa Zone, South of Gojeb region with its special place "Mankira" in Bunno kebele[24]. According to Kaffa tradition, coffee was discovered by goatherd man called Kalli or Kalliti in about $2^{\text {nd }} A$. D. The following legend states how coffee was discovered there: “... It was sometimes about $2^{\text {nd }}$ century $A$. D that a goat shepherded called Kallil or Kalliti noticed the special smell of coffee from breath of goats. Kalli followed route of the American Research Journal of History and Culture

Page 3 
Discourse Analysis of Origin and Distribution of Coffee Arabica

goats and observed the type of plant leaves which the goats anxiously ate. Kalli then picked some of these leaves. He first observed the stimulating properties of wild coffee..." [25].

According to this local tradition among the many type of vegetation's, the special reward that Kaffa presented to the world is "coffee". The word coffee in Kaffa language, Kafinono is "Bunno". In Kaffa, a place called Mankira to the southeast of Bonga is said to be the place where coffee was originated [26]. Kaffa scholars and local tradition have depended on controversial evidences. First, the name coffee was initially derived from the term Kaffa and other languages took from it. For example, in Chinese it is "kaifye", in Danish "kaffe', in Finland "kavie", in Hungarian "kave", in Italian "café" and in English speaking countries it is called "coffee". In Ethiopia alone there are different names. For example, Bunna for Amharic, Buna for Afaan Oromo, bun in Tigrinya, bunna in Amharic, buna in Afan Oromo, tukke in Gamo, Wälläyta, Kullo and qahwa in Harari. There is no strong evidence that show the Amharic term "Bunna" and "Afan Oromo term "Buna" have been derived from Kaffa's term called "Bunno". It is still controversial evidence which might have existed between "Bunna", "Bun", "Bune", "Buna" and "Bunna" [27]. Well distilled scientific evidence reveals that, the name "coffee" was derived from the term "Coffien" which means the stimulant substance naturally found in coffee and tea. Others said, the word "coffee" is derived from the Turkish word kahveh, which is rooted in the Arabic word for qahwah, meaning wine.

The second locally oriented source is the current Jimma Zone, Gomma district of Coccee Guddaa kebele at a site called 'katta muиduu ga'a'. According to Oromo tradition, Kalid, was goatherd man and discovered coffee around 1000 years ago on a small hill called Katta mиидиu ga'a in Coccee Gudda kebele of Gomma district. This legend also states that Kalid was an Arab Muslim fortune seeker who came to Gomma around the end of the $9^{\text {th }} \mathrm{A}$. D.The legend of Kalid as said the by Oromo of Gomma is quoted as below: “...One day Kalid saw his goats behaving in unusual manner, he observed his goats showing in abnormally energetic manner skipping, rearing on their hind legs and bleating loudly. He noticed they were eating the bright red berries on the green bushes near by his pasture. He himself tried a few and soon felt novel sense of delight [28].

Thus, we realize from this legend that, there is confusion with regard to the birth place of coffee and the first people used coffee. In Ethiopian coffee dictionary, there are different terms for coffee used by Ethiopian ethnic groups. For instance, bunin Tigrinya, bunnain Amharic, buna in Afan Oromo, tukke in Gamo, Wälläyta, Kullo and qahwa in Harari., tika in Me' en or buno in Gurage. These terms correspond to the coffee bean, and as the word bun both used in Arabic and Ethiopian languages [29]. As Bekele states, the term "bunna" is simply a name which had been given to Kaffa's women who prepared coffee for long distance northern traders of $19^{\text {th }} \mathrm{c}$. This source argued that it was the northern traders who had initially declared the name "Bunna" in Kaffa region and no coffee name in Kaffa region before $19^{\text {th }} \mathrm{c}$. If so, there is no evidence as other languages borrowed from the term Bunno[30].

This implies that the name 'Bunna' might have not been in use before the beginning of the long distance trade. Under these circumstances, other scholars agreed as Kaffa emerged in the $14^{\text {th }}$ century with the formation of the Minjo dynasty and long distance trade was only a phenomenon of the $19^{\text {th }}$ century. As a different source reveals Christianity was introduce to northern Ethiopia in the $4^{\text {th }}$ century AD and Kaffa was Christian during the medieval period (1270-1855). On the other hand the use of coffee became popular in Christian world and Ethiopia only after the $17^{\text {th }}$ century [31]. As Oromo traditions reveals, the Oromo called coffee "Buna" since the $10^{\text {th }}$ century A.D. They still have no other name for coffee. As a result, "Buna" is the only word that stands for coffee throughout Oromia region. Thus, the Amharic name "Bunna" was either derived from an Oromo word "Buna" or it might have adopted from Yemen, "Bunn" [32]. According to Limmu oral tradition, it is very different coffee tree which is not found elsewhere in southwestern Ethiopia. Even if, contradicting locations emerged between these two local areas in southwestern part of Ethiopia based on existing evidence, it is a clear as the Ennarya regions of Limmu awraja was the origin of coffee Arabica [33]. 
Discourse Analysis of Origin and Distribution of Coffee Arabica

The Spread of Coffee around the world as a Beverage Crop

Among the many crops most important gift of Ethiopia to the world which had tremendous economic, social and spiritual impact on many people of different geographical locations, cultural background and psychological makeup is coffee (Coffea Arabica L.) Primitive man must have suffered from famine and hardship in each generation because of natural disasters, such as drought, floods, disease and pests, the destruction of wild animals, and prolonged tribal wars. Because of these they forced to survive by feeding on the products of wild plants. To do so, birds and animals were watched to discover what they fed upon, and everything must have been tried and chewed to see if it was suitable for eating [34].

The first use of coffee started a long time ago by the indigenous people of Ethiopian called Oromo. The Oromo's, one of the ethnic groups in Ethiopia, are reported to have had a special diet with a coffee for use on their long trips. They used to carry ground roasted coffee mixed with oils or fats, made up into balls shapes to comfort and stimulate them during hard journeys [35]. They used various parts of the coffee plant: leaves, fruits and seeds for food [36]. It is still uncertain when and how coffee came into use as a beverage crop. No convincing evidence to explain when human beings first domesticated coffee. Instead, there are various legends which state the use as a beverage. In spite of these legends, different scholars have approved that it was the Oromo people who for the first time used coffee as food crop. For instance, Gutu states that "Around $10^{\text {th }}$ century A.D coffee was chewed by nomadic Ethiopian people called Oromo who combine the ripe berries of coffee with animal fat which they form into round balls that they carry on their journeys for use as a food and stimulant effect". But, they did not begin to use as beverage [37].

Additionally, according to [38 ] , the use of coffee as food was introduced from Africa to Arabia in pre-Islamic days. Among many travelers, James Bruce, who travelled in Ethiopia, between 1768 and 1775 also reported in the Merid's work the same thing that "it was the Oromo people who first used coffee as a food from a beans which they mix with butter, which they claimed kept them in strength and sprits during the whole days tiredness, it is better than a leaf of bread or a meal of meat". They used it during their long journey to help them to survive [39], [40].

Internally, it is believed that it was during the Oromo expansion of the $16^{\text {th }}$ century that, the spreading out of coffee tree and coffee drinking habit expanded [ 41], [42 ]. But in some areas where people followed Orthodox religion of our country coffee drinking was not known until the end of the $17^{\text {th }}$ century. Because, before the end of the $17^{\text {th }}$ century the Ethiopian Orthodox Church prohibited Christians from drinking coffee, smoking tobacco and chewing chat [43], [44 ]. Later, coffee is said to have been spread throughout Ethiopian high lands by long distance caravan merchants of the $19^{\text {th }}$ century. Whereas at the end of 19th century, Amharas of Shewa kingdom conquered these regions developing considerably coffee exploitation and commercialization [45].

It was probably Oromo traders who actually disseminated it to some parts of the north. These traders took the beans of coffee and named it "Buna" in the memory of Genne-Bunno or Genne-Bunne, the wife of Kaffa ruling kings who prepared coffee for long distance traders and invited them to drink this new drink [46].As oral tradition reveals, for Oromo, coffee has not only economic importance but also long historical, cultural and religious values. For instance, the 'buna alaa' ceremony is age old Oromo cultural practice. It prepared for numerous cultural and religious feasts like the gadaa, muudan, buttaa, gumaa reconciliation, wedding and other traditional ceremonies. This further implies that coffee is an inseparable plant from popular and long aged Oromo cultural and religious life [47].In addition to the customary cup use, coffee is consumed in various forms in Ethiopia. Each form of use has been also reported to have its own name. These forms are Buna Qalaa (ripe-red fruits boiled with fresh butter) ; Buna Basso( fruits or beans roasted or boiled with butter forming part of other food items); Buna Keshir or Hoja - roasted pulps or and beans drunk alone or with milk, 
Discourse Analysis of Origin and Distribution of Coffee Arabica

butter, honey or salt; Kuti (dried and pounded coffee leaves boiled with milk) and Buna Arake( liquor made from roasted coffee beans). Coffee is also consumed spiced with nutmeg, cardamom, ginger, cinnamon, fennel, cloves, black or ground hot red pepper [48].

Aside from its use as a beverage and food, coffee provides pulp and parchment which are used as manure, mulch, animal feed or fuel [49]. Fresh coffee pulp is used for preparation of compost and tannin for tanning leather. Coffee was also used in early medicine in Arabia, Europe and America for many purposes [50]. It was used to comfort the brain, against pains in the head, lethargy and cough. It was and still is useful in so bering drunken people and in preventing sleepiness. It was also considered useful against rheumatism, worms (for children) and it was considered a strong ant hypnotic. It is still being used by many people to relieve headache in Ethiopia. The wood from the coffee trees can be used for fuel or construction purposes while nectar from the flowers is used by bees to make honey. The trees also have an indirect contribution to soil conservation as they provide shelter to the soil from the damaging heavy rain, hail and wind [51].

However, it is not yet clear how coffee was taken from its birth place of Ennarya region of southwestern forest of Ethiopia to where it was first cultivated in Yemen and spread to other parts of the globe. But it was believed that coffee was stolen by Arab merchants, who took and planted it for the first time in Yemen [52]. Scholars suggested that Arab slave raiders may have noted these practices when they captured slaves with dried coffee fruits in their possession. This might have open the way for the introduction and cultivation of coffee in Arabia. To invalidate the above view, some have suggested that, coffee came to Arabia through Persia. According to these sources during the Sassanid Dynasty of Persia there was an invasion of Yemen. These conquerors travelled overland up to the Nile Valley. It was probably these conquerors that took this important plant from Harar in Ethiopia in about $575 \mathrm{~A}$. D and planted it in the Yemen. But it was not clear how and why these conquerors came to Ethiopia and took coffee to Yemen. Still there is no tangible reason how coffee was introduced to Arabia indirectly from Persia rather than directly from Ethiopia, across very short distance to Yemen. So, there is a sort of confusion in this view [53].

[54] gave two possible explanations about the introduction of Arabian coffee into Arabia. In his first explanation, it introduced by Persian invaders. He stated that during the Sassanid dynasty of Persia, therewas an invasion of Yemen. ThePersian conquerors travelled overland from Persia and up the Nile Valley and stayed for a long time in the territory they won, and made expeditions into Ethiopia [55]. During this time, the Persians took with them to their countries and later it introduced to Arabia. So, coffee may have come to Yemen as part of these invasions. Inhis second explanation, he noted thatEthiopians had at one time travelled out of Africa, across the narrows of the Red Sea to Arabia Felix (now Yemen). It was during these days that coffee introduced to Arabia. However, it is not clear when and why Ethiopian moved to Yemen. It seems that Ethiopian adventurers andreligionists brought with them the first coffee seed from Ethiopia. There are differences in opinion about the date of introduction of coffee into Arabia[ 56]Wellman (1961) considers the first introduction was about 575 (A.D) [57] wrote that the Arabs took coffee from Ethiopia and planted it in Arabia in about the eleventh century. In the $14^{\text {th }}$ Century the Arabs were took secretly coffee plants from Ethiopia and cultivated coffee plants in Yemen today. It was from there that they took it back and planted it in Harar, southeastern Ethiopia in the fifteenth century.

But [58], states that there is no sound evidence of coffee in Arabia during the thirteenth century. More recently, [59] acknowledged that the wild Arabicacoffee is indigenous to Ethiopia. He noted that it was discovered in 850 (A.D.) and was cultivated in Harar during its occupation by the Arabs. In the 14th and 15th centuries, Arabs brought coffee from south western Ethiopia to Yemen where they developed its culture. Then Islam spread a huge propaganda on coffee consumption, essentially Ethiopian Muslim traders, even Arabs, who exported 
Discourse Analysis of Origin and Distribution of Coffee Arabica

coffee from its production places to Red Sea or Aden Gulf ports [60].The exact date when coffee was first drunk is not known. However, it is well knownthat the drink was first discovered in Arabia about the middle of the fifteenth century.In the beginning a mixture was made from the thin sweet pulp of the fruitsof Arabica coffee, which the Arabs called 'kahwah', a name they used for wine or 'wine of Araby' [61]. Later, the art of roasting and preparing a coffee drink hadspread into countries bordering Arabia, and possibly first of all in Persia [62]. The habit of coffee drinking then spread all over the Moslem Middle East. For instance, it reached Cairo in 1510, Constantinople and Turkey in 1554 and Venice in 1560 [63].

By the middle of the $15^{\text {th }}$ century coffee drinking became popular throughout Arabia. However, towards the end of fifteenth century (1470-1500) it reached Mecca and Medina. In 1475 Ottoman Turks introduced coffee to Constantinople. A coffee shop called "Kiva Han" opened in Constantinople. Later in about 1510 it reached Grand Cairo in Egypt and from the mid $17^{\text {th }}$ century onwards, coffee had spread throughout the world [64]. After the Arabs learned to boil water and adding to its crushed green coffee beans, they roasted the beans and ground them up to produce soluble beverage. As coffee drinking habit continued to spread out throughout Arabia, leaders began to see the coffee houses as a danger for their power. Soon, the rulers tried to shut down the "qahvehkaneh" in order to avoid conspires and revolts against them, but instead the coffee houses became increasingly well-liked and very difficult to control them[65].The Sufi's used the drink to keep them alert during their night-time devotions. It is most likely that coffee spread from Mocha into Egypt, North Africa, then the Middle East, Persia and Turkey. In many locations coffee would be banned by the orthodox imams but most of such bans were overturned in the mid 16th Century by order of the Ottoman Turkish Sultan Selim I and the Grand Mufti Mehmet Ebusuud al-Imadi issued a fatwa permitting coffee drinking [66].

The spreading of coffee drinking to many countries created a lucrative trade for the Arabians, which they guarded jealously for many years [67]. The raw beans were not allowed out of the country of cultivation without first being steeped in boiling water or heated to destroy their germinating power. Moreover, strangers were not allowed to visit the plantations. However, the channels through which coffee was traded from Arabia and the Middle East to Europe were not easy in those early days and the product was costly to import. Because of its increasing importance both as a beverage and a source of income, several expeditions were sent by the Dutch, the French and the British to obtain seed or planting material from Arabia. Attempts were also made to establish coffee in Europe [68 ]. The first person who was successful in his attempt to steal coffee from Arabia, Mecca, was an Indian pilgrim called Baba Budan [69], [70],[71],[72]. He is said to have smuggled out seven coffee seeds, strapped to his belly, from Mecca and planted them at Chikmagalur in the mountains of Mysore (India) at about 1600 A. D. From there coffee spread to other parts of India, but it was not until the early nineteenth century that the British began to develop coffee estates [ 73 ].

Furthermore, European colonialists first saw coffee in Arabia and developed it throughout the world. It was supposed that Venetians first introduced coffee to Europe. In1615 the first coffee was introduced to Europe when a shipment from the Yemen port of Mocha arrives in Venice. Traders and voyagers had been bringing news of this admired beverage crop of Arabia to their European homelands [74].It was a Venetian merchant brought coffee beans from Mocha to Europe in 1615 [75]. The first coffee from Mocha was brought to Holland by Pieter van den Broecke in 1616 [76]. Drinking of coffee was later introduced to other countries of Europe at different times: to Rome in 1625, France in 1671, Oxford in 1650, London in 1652, Marseilles in 1659, Amsterdam in 1663, Paris in 1675, Hamburg in 1679, Vienna in 1683, Leipzig in 1694, New York in 1688, Russia in about 1700, Stuttgart in 1712, Berlin in 1721, Sweden and Denmark in 1756[77], [78], [79].

In 1600 Portuguese, Spaniards and Dutch traders spread it to the America from Amsterdam. Just four years later the British took control of Amsterdam and renamed New York. Coffee is already a popular drink among the inhabitants by them. The colony of Virginia at Jamestown was founded with the help of Captain John Smith, 
Discourse Analysis of Origin and Distribution of Coffee Arabica

who is said to have introduced the first coffee to North America in1607.Coffee was introduced to Brazil in 1727

[80] from French Guiana by Francisco de MeloPalheta (aBrazilian Army Officer) who was sent there to settle the boundary dispute created between the Dutch and French Guianas[81], [82]. In the meantime, lieutenant established a good relationship with the wife of the governor of Guiana, who gave him as a sign of admire in which she had hidden coffee cuttings and seeds. The coffee brought by de MeloPalheta led to the beginning of Brazil's coffee industry, which became one of the world's great coffee growing empires [83].

Coffee started to be grown for profit by Europeans both in Sri Lanka and India.This began to break the dependence of Europe on coffee from Arabian ports and also started wider use of the beverage. After seeing its good production and development in Sri Lanka, the Dutch continued their efforts to obtained coffee plants from the Malabar Coast in India to be taken to Java (in Indonesia) in 1696. Thesewere the first coffee plants introduced into the Dutch East Indies (now Indonesia) [84]. In 1714, one coffee tree was sent to king Louis XIV of France who sent it to the Jardin des Plantes in Paris, where it was received by AntoinedeJussieu. Jussieu gave this coffee tree the name Jasminum Arabic umlaurifolio. The French continued their effort and became successful in 1718 when they tried a third time. This time several plants, originally obtained from Ethiopia, were taken from Mocha [85]. As early as 1718, the Dutch had begun planting coffee, brought from Amsterdam. This was the first coffee planted on the continent of South and Central America.

\section{Conclusion}

Ethiopia is the primary center of genetic diversity of coffee Arabica. As many scholars revealed that coffee was first discovered in the forest of southwestern part of Ethiopia, particularly the northern Kaffa province; the former Ennarya regions. However, there are two competing local areas, which have recently emerged in Southwestern parts of Ethiopia. These are Mankira of the present Kaffa zone and Coccee of the present Jimma zone. However, these study showed that the former Limmu Awraja of Gomma district, Coccee Guddaa kebele at a site called 'katta muuduu ga'a' is said to be the historical origin of coffee Arabica. There is no enough studies showing coffee distribution around the world. It is not yet clear how coffee spread from its birth place of Ennarya regions to other parts of Ethiopia. It is believed that it was during the Oromo expansion of the $16^{\text {th }}$ century that coffee spreading out in Ethiopia regions. Later, it was probably long distance Oromo merchants of the $19^{\text {th }}$ century who disseminated the plant. These traders took the beans of coffee and named it Buna. As oral tradition reveals, for Oromo, coffee has not only economic importance but also, it has long historical, cultural and religious values. For instance, the 'buna qalaa'(slaughtering coffee) ceremony is age old Oromo cultural practice. It prepared for numerous cultural and religious feasts like the gadaa, ateetee, buttaa, gumaa reconciliation, wedding and other traditional ceremonies. However, it is not yet clear how coffee was taken from its birth place of Ennarya regions to where it was first cultivated in Yemen and spread to other parts of the globe. But it was believed that coffee was stolen by Arab merchants, who took and planted it for the first time in Yemen. Still, the exact date when coffee was first drunk is not known. However, probably coffee drink was first discovered in Arabia about the middle of the fifteenth century. Furthermore, European colonialists first saw coffee in Arabia and developed it throughout the world.

\section{REFERENCES}

1. Fuad Abba Fita. (2010). "Studies on the Diversity of Insect Peast in Wild and Cultivated Coffee Plantation in and around Jimma, southwest Ethiopia", MSC Thesis, AAU.

2. Ermias Demere. (1985). "Productivity study of resource and income in the growing farms of Kaffa administrative region”,M.Sc Thesis AAU.

3. Tesfaye Alemu and Ibra Limosker.(2000). "The states of Coffee Berry Disease in Minor coffee growing 
Discourse Analysis of Origin and Distribution of Coffee Arabica

regions" in the book proceeding of the workshop on the control of Coffee Berry Disease in Ethiopia, Addis Ababa.

4. Bartles, Lambert. (1990). Oromo Religion, Myth and Rites of the Western Oromo of Ethiopia. An Attempt to Underst and. Dietrich Reim er Verl ag: Berlin.

5. Wrigley Gordon. (1986). History of coffee. Linton Cambridge, p.10.

6. Endalkachew Lelisa.(2013 ). A Historical Survey of Coffee Production and Marketing in Jimma and LimmuAwräjäs, ca.1800-1991, MA Thesis, Jimma University, Department of History and Heritage Management, p.27.

7. De Salvia C Martial.(1901) Ancient African people the great Nation: the Oromo people, parisFrance,p.112.

8. Mekonen Hailemichael. (2009). Influence of Genotype, Location and Processing methods on the Quality of Coffee (coffeaarabica l.) M.sc. ThesisHawassa University, Ethiopia.

9. MC Cann, James. (1995). People of the plow: Agricultural history of Ethiopia 1800-1990 wisconsin press.

10. Mohammed Hassen (1994). The Oromo of Ethiopia: a history 1570-1860. Camberidge, University.

11. Huntingford. G. W. B.(1969). The Galla of Ethiopia, the kingdom of kaffa and Janjero (London.).

12. Demel Teketay. (1999). History, botany and ecological requirements of Coffee Article, Botswana University of Agriculture and Natural Resources (BUAN).

13. Haarer, A. E.(1962) ). Modern Coffee Production. Leonard Hill Book Limited, London,

14. MC Cann, James.(1995). People of the plow: Agricultural history of Ethiopia 1800-1990, wiscons in press.

15. Endalkachew Lelisa.(2013). A Historical Survey of Coffee Production and Marketing in Jimma and Limmu Awräjäs, ca. 1800-1991, MA Thesis, Jimma University, Department of History and Heritage Management.

16. Bekele Woldemariam.(2002). The history of the kingdom of Kaffa: the birth place of coffee 1390-1935, Addis Ababa ARCCIKCL.

17. Tsegaye Tesfaye.(2006). Impact of coffee price fluctuation on the Ethiopian Coffee Plantation Enterprise" BA Thesis, Jimma University.

18. Laurent Bossolasco.(2009). Limu Coffee. A study case on Coffee (Coffeaarabica L.).

19. Tamirat Tessema.(2006). "Impact of international coffee price fluctuation on Economic Development of Jimma Zone" BA Thesis , JimmaUniversity, Department of Economies.

20. Gutu Degefa.(2006). "Coffee export and Economic growth in Ethiopia” A Research Report. BA Thesis , Jimma University.

21. Wellman, F. L.(1961). Coffee: Botany, Cultivation and Utilization. Leonard Hill(Books), London.

22. Wrigley, G. (1988). Coffee.Tropical Agriculture Series. Longman Scientific andTechnical.Copublished in the United States with John Wiley and Sons, Inc., NewYork.

23. Merid WoldeAragey.(1988). The Early history of Ethiopia Coffee Trade and the rise of Shawa: Journal of Great Britain African history. 
Discourse Analysis of Origin and Distribution of Coffee Arabica

24. Pankhurst, Richard.(1990). A social History of Ethiopia: The Northern and Central Institutes of Ethiopia studies, Addis Ababa, Ethiopia.

25. Mesfin Amaha.(1991). General Introduction: An overview on the status of coffee, tea and spice in Ethiopia. Proceedings of the first workshop on production constraintassessment of coffee, tea and spices. Jimma College of Agriculture, Jimma.

26. Meyer, F. G. (1965). Notes on Wild Coffea Arabica from South-western Ethiopia, with some Historical Considerations. Economic Botany 19: 136-151.

27. Southard, A. E.(1918). The Story of Abyssinia's Coffees. The Tea and Trade Journal 34 (3): 212-215 and 324- 329.

28. Smith, R. F. (1985 ). A history of coffee. In Clifford, and Willson, (eds.), Coffee:Botany, Chemistry and Production of Beans and Beverage, Croom Helm Ltd, England.

Citation: Endalkachew Lelisa Duressa. "Discourse Analysis of Origin and Distribution of Coffee Arabica". American Research Journal of History and Culture ; V4, I1; pp: 1-10

Copyright (c) 2018 Endalkachew Lelisa Duressa. This is an open access article distributed under the Creative Commons Attribution License, which permits unrestricted use, distribution, and reproduction in any medium, provided the original work is properly cited. 